SECTION 5. Innovative technologies in science.

Andrey Mastislavovich Korneev candidate Technical Sciences, teacher at the University, Lipetsk State Technical University, Russia weenrok@mail.ru

Faisal Abdo Ali Al-Saeedi

Postgraduate, Lipetsk State Technical University, Russia faisa1853450@mail.ru

Ghassan Mohsen Al-Sabry

Postgraduate,

Lipetsk State Technical University, Russia lion100@mail.ru

Abdullh Mohammed Mohammed Nagi

Postgraduate,

Lipetsk State Pedagogical University, Russia

nagi_farad@mail.ru

\title{
THE ANALYSIS OF TECHNOLOGICAL TRAJECTORIES BASED ON THE TREE CONSTRUCTION
}

Abstract: This paper presents an algorithm for choosing the optimal technological regimes, which allow to link technological factors and the quality of products, provides an example of the construction of the tree of transitions for a given set of initial values of technological parameters.

Key words: analysis of technological, technological trajectories, tree construction.

Citation: Korneev AM, Al-Saeedi FA, Al-Sabry GM, Nagi AM (2014) THE ANALYSIS OF TECHNOLOGICAL TRAJECTORIES BASED ON THE TREE CONSTRUCTION. ISJ Theoretical \& Applied Science 9 (17): 46-49. doi: http://dx.doi.org/10.15863/TAS.2014.09.17.7

In real production conditions, divided by the number of stages, a simple implementation of technology cannot guarantee the products of sufficient quality. This can occur due to the influence of a large number of technological parameters, some of which cannot be described production instructions.

Thus, the products of inadequate quality may occur due to changes in production conditions, the drift of raw materials, changes in requirements to properties and in violation of technological regimes. When choosing the best technologies and the development of control algorithms, it is necessary to consider the absence of sufficiently strong functional links between technology (the technology factors) and quality of hire. It is also necessary to take into account ambiguous reference (in the form of many different intervals) values of quality indicators. Hence the need for management is to determine the values of technological factors, which are represented as intervals of values.

Inputs, states and outputs can have a different number of the studied range of changes (alphabets).

In general, the production process has multiple inputs, states (technological factors), divided into conversions or units, and outputs, and alphabets of the inputs, states and outputs can have a different atomicity.

Combination of technological factors' alphabets shape the technological trajectory. The implementation of each such trajectory allows to obtain a certain level of properties and to estimate the costs of its implementation. 
The properties are in most cases is random or, at least, is not strictly deterministic. Consequently, it is possible for each mode to set the probability of obtaining a certain level properties, i.e. the probability of different combinations of alphabets of the output properties. $\mathrm{R}$ is selected for the analysis of quality indicators. In each experiment, the number of these indicators, that correspond to the requirements of standards, are different.

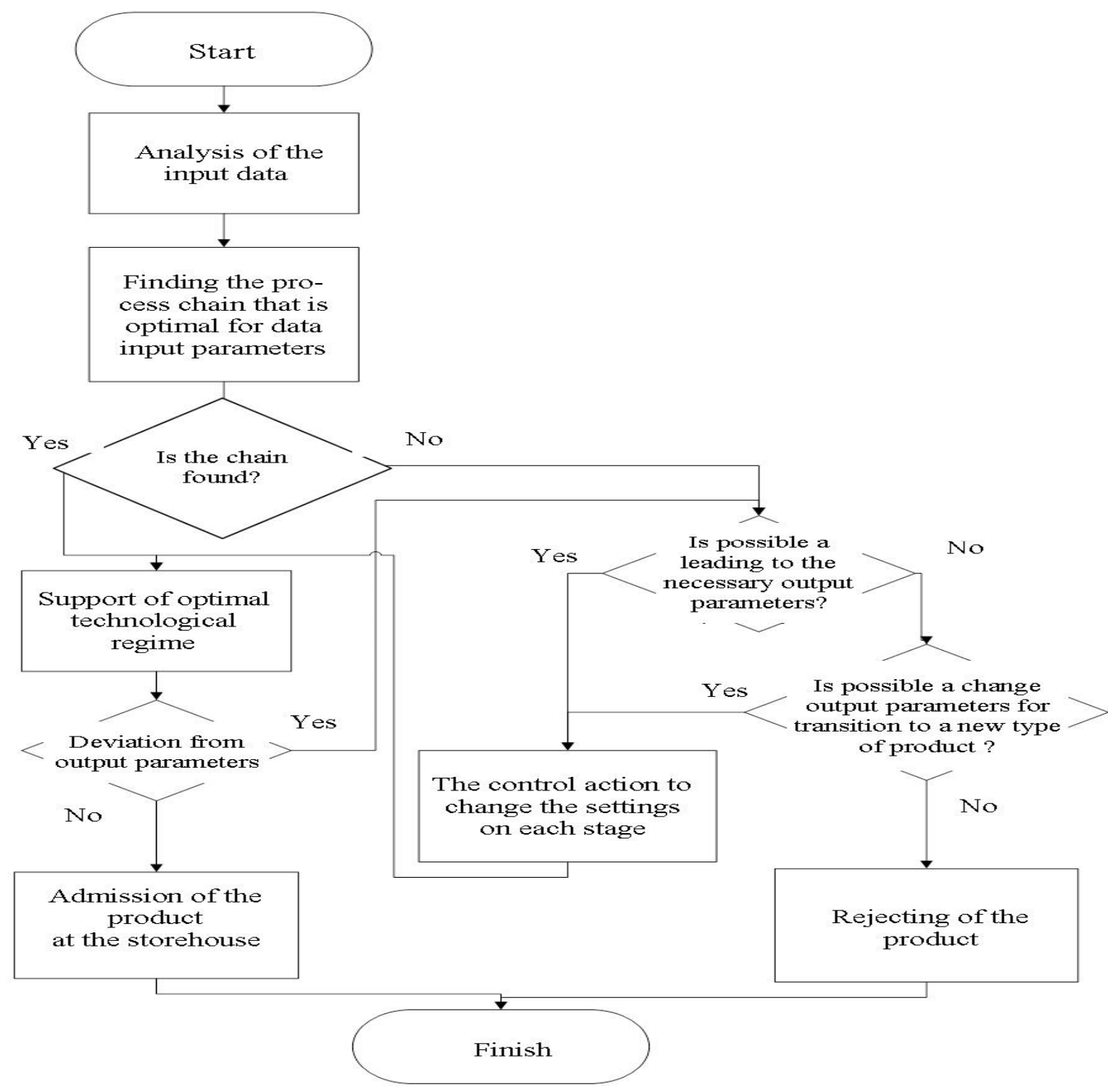

Figure 1 - The algorithm maintain optimal technological regime.

We will develop the algorithm for choosing the optimal technological regimes, which allow to link technological factors and product quality.

- After you build distribution trees we have a visual representation of the process chain, which allows us to trace the entire path of the material (product) for all units (at all stages).

- Each stage should be applied by the control action such that the process parameters were within the maximum close to the interval, which maximizes the probability of obtaining products of proper quality.

- If the output values don't get to the region corresponding to the necessary parameters, it is necessary to consider the possibility of changing the form of the output product. For example, 
if the thickness of rolled product corresponds to the values needed in the manufacture, you can change the output to the appropriate kind that complies with really output parameters.

- If you cannot change the output type of product (too strong deviations of technological values from valid parameters), this product is rejected and, if possible, goes to further reprocessing.

Figure 1 shows the block diagram showing the implementation of this algorithm.

We will make up the trees of possible outcomes after the first, second and third stages based on the calculated statistical data.

Figure 2 shows an example of constructing a tree of transitions for a given set of initial values of technological parameters at the first stage. The possible options for continuing the technology and the number of realized experiments are indicated.

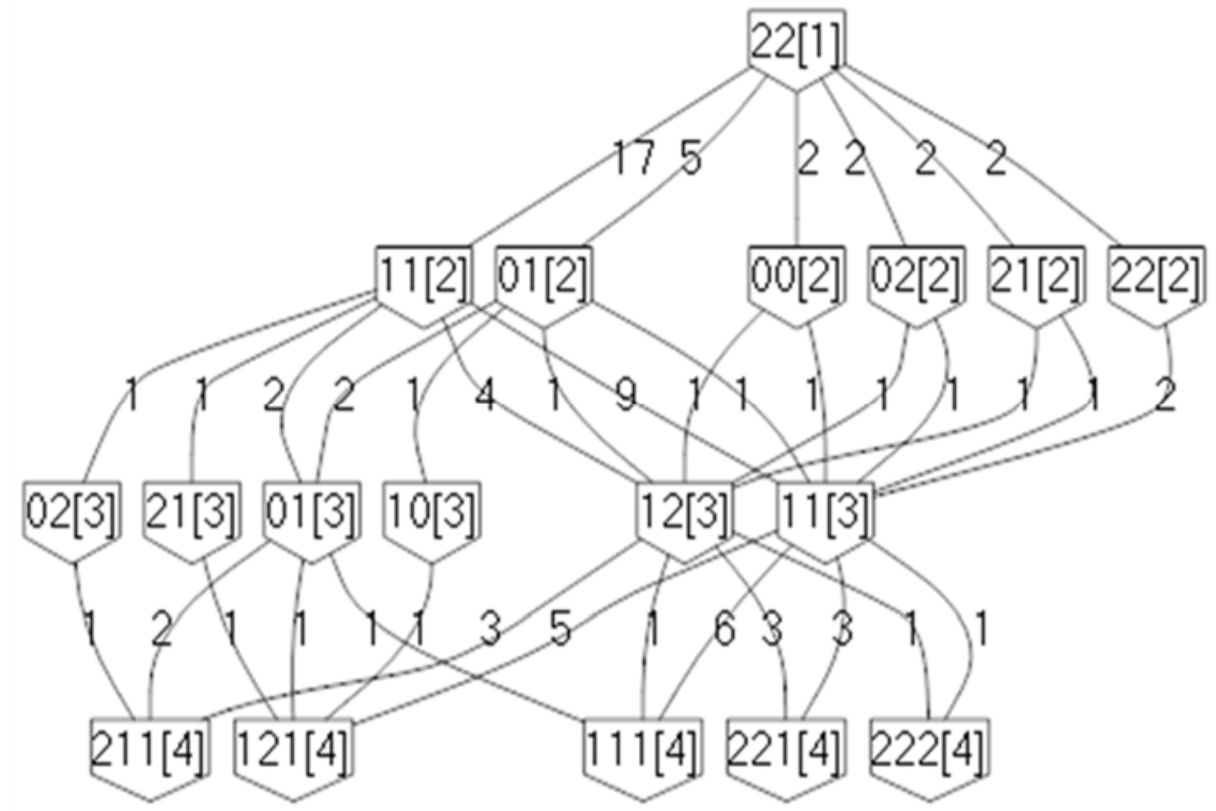

Figure 2. The tree of outcomes for the first stage with the starting point 22.

The developed approach allows determining the optimal trajectory of processing of products and provides the ability to adapt to the changing conditions of production due to the choice of the most favorable continuation.

\section{References:}

1. Korneev AM, Al-Saeedi FA, Al-Sabry GM, Nagi AM (2014) Blocks of structural modeling and search optimization discrete cell-hierarchical systems using computer information processing techniques. «Modern mathematics in Science» Caracas, Venezuela. International Scientific Journal Theoretical \& Applied Science 6 (14): 14 -17. doi: http://dx.doi.org/10.15863/TAS.2014.06.14.4

2. Korneev AM, Butakov VV, Filatov AA (2014) Discrete-variable modeling of technological process. «Scientific technologies of the future», Linköping, Sweden. International Scientific Journal Theoretical \& Applied Science 2(10), pp. 35- 39. doi: http://dx.doi.org/10.15863/TAS.2014.02.10.5

3. Korneev AM, Al-Saeedi FA, Al-Sabry GM, Smetannikova TA, Nagi AM (2014) Discrete modeling of complex manufacturing systems. «Economy, technology, education and prospects for 2014», Malmö, Sweden. International Scientific Journal Theoretical \& Applied Science 1(9), pp. 32- 35. doi: http://dx.doi.org/10.15863/TAS.2014.01.9.5 
4. Korneev AM, Al-Sabry GM, Al-Saeedi FA (2013) The optimal strategy for adapting technological regimes in discrete systems. Proceedings of the 4rd International Academic Conference «Applied and Fundamental Studies» Vol. I, St. Louis, Missouri, USA, pp.264267.

5. Korneev AM, Blumin SL, Smetannikova TA (2013) Numerical methods of search engine optimization of discrete cell-hierarchical systems. News of higher educational institutions of Chernozemia, No.3, pp. 21-26.

6. Korneev AM, Miroshnikova TV (2010) Automated system of prognosis of resources expenditure on production of metal output. Proceedings of the 12 International Workshop on Computer Science and Information Technogies CSIT'2010. Moscow-St.Petersburg, Russia 2010, pp.47-50.

7. Korneev AM (2008) Description of technologies using finite state machines. News of higher educational institutions of Chernozemia, No. 3, pp. 56-61.

8. Korneev AM, Miroshnikov TV (2008) Method of finding the optimal boundaries of the factors for through technology. Control systems and information technology, No.3(33), pp.93-96.

9. Korneev AM (2009) Identifying Methods of Through Technology Production of Steel Products: monograph. Lipetsk State Pedagogical University. Lipetsk: LSPU, 286.

10. Blumin SL, Korneev AM (2005) Discrete modeling of systems of automation and management: Monograph, Lipetsk Ecologic Humanitarian Institute. Lipetsk: LEHI, 124. 